\title{
PEMBERIAN KOPI ARABIKA GAYO PASCA STRESS FISIK AKUT SUBMAKSIMAL TIDAK MEMPERCEPAT PENURUNAN KADAR LAKTAT DAN PENINGKATAN GLUKOSA DARAH PADA ORANG TIDAK TERLATIH
}

\author{
Hadyan Zulfahmi ${ }^{1}$, Hadiq Firdausi ${ }^{2}$, Purwo Sri Rejeki ${ }^{3}$, Lilik Herawati ${ }^{3,4^{*}}$ \\ ${ }^{1}$ Program Pendidikan Kedokteran, Fakultas Kedokteran, Universitas Airlangga, Indonesia \\ ${ }^{2}$ Departmen Kedokteran Interna, Fakultas Kedokteran, Universitas Airlangga, Indonesia \\ ${ }^{3}$ Department Fisiologi, Fakultas Kedokteran, Universitas Airlangga; Sport Clinic, Fakultas \\ Kedokteran, Universitas Airlangga- Dr Soetomo, Indonesia \\ ${ }^{4}$ Sport Clinic, Fakultas Kedokteran, Universitas Airlangga- Dr Soetomo, Indonesia
}

*corresponding author: lilik_heraw@ fk.unair.ac.id

\begin{abstract}
Abstrak
Jaringan otot memiliki fungsi penting untuk berkontraksi. Ketersediaan energi sangat terbatas dan akan habis untuk kontraksi otot yang membutuhkan tenaga besar dalam waktu yang singkat. Energi didapatkan dari proses fosforilasi non-oksidatif (Anaerob) yang menghasilkan asam laktat. Kafein pada kopi arabika gayo akan meningkatkan oksidasi asam lemak dan menurunkan oksidasi karbohidat. Hal tersebut berdampak pada penurunan laktat darah. Konsumsi kopi menurunan laktat darah sehingga mempercepat recovery kelelahan setelah latihan fisik. Tujuan penelitian ini untuk mengetahui pengaruh pemberian kopi arabika gayo pasca stress fisik akut submaksimal terhadap kadar laktat dan glukosa darah terhadap proses recovery otot setelah latihan fisik pada orang tidak terlatih. Penelitian ini adalah eksperimetal dengan metode post-test only control group design. Sampel penelitian adalah laki laki dengan usia 21-27 tahun dan diambil dengan teknik simple random sampling. Pengambilan data dilaksanakan di Laboraturium Olahraga Universitas Surabaya pada Desember 2018. Hasil penelitian ini dianalisis dengan SPSS 17. Hasil penelitian menunjukkan terjadi penurunan laktat dan peningkatan glukosa darah pada kelompok kontrol $(1,609 \pm 1,2597 \mathrm{mmol} / \mathrm{l} ; 15,182 \pm$ $15,2041 \mathrm{mg} / \mathrm{dl}$, kopi $1(2,527 \pm 1,2744 \mathrm{mmol} / ; 15,727 \pm 9,8396 \mathrm{mg} / \mathrm{dl})$, kopi $2(1,873 \pm$ $1,3350 \mathrm{mmol} / \mathrm{l} ; 12,727 \pm 8,5684 \mathrm{mg} / \mathrm{dl})$. Pemberian kopi arabika gayo pasca stress fisik akut submaksimal setelah lathan fisik dan pada orang tidak terlatih tidak memiliki pengaruh menurunkan kadar laktat darah dan meningkatkan kadar glukosa darah
\end{abstract}

Kata Kunci : Kopi arabika g ayo, kafein, laktat darah, glukosa darah, kelelahan 


\section{Pendahuluan}

Jaringan otot mempunyai fungsi

untuk berkontraksi dan kontraksi otot memerlukan transmisi neuromuskular, ion kalsium, dan energi. Energi yang dibutuhkan berupa adenosin trifosfat (ATP) ( Strojnik , 1998). Ketersediaan ATP akan habis dalam waktu singkat untuk kontraksi otot dengan jenis kontraksi yang membutuhkan energi yang besar. Setelah itu, kebutuhan energi berasal dari sintesis ATP melalui jalur oksidatif kreatin fosfat (CP). Selanjutnya, ATP diperoleh dari proses fosforilasi nonoksidatif (Anaerobik) ( Silverthorn , 2004; McArdle , 1996).

Metabolisme

anaerobik menghasilkan ATP dan sisa metabolisme berupa asam laktat. ( McArdle 1996; Billat , 1996). Asam laktat adalah produk akhir dari proses metabolisme anaerobik. Akumulasi laktat dalam darah berbahaya karena dapat menyebabkan penurunan kinerja fisik dan kelelahan ( Widiyanto, 2009).

Minuman stimulan banyak dikonsumsi masyarakat sebagai minuman suplemen penambah tenaga dan mengurangi rasa lelah akibat kerja fisik. Salah satu suplemen stimulan adalah kafein yang terdapat pada kopi arabika. Kandungan kafein dalam kopi dapat merangsang sistem saraf pusat sehingga meningkatkan kadar adrenalin plasma. Kafein akan bekerja secara sinergis dengan hormon adrenalin dan mempengaruhi pelepasan FFA (asam lemak bebas) sehingga terjadi peningkatan oksidasi FFA (Acheson et al., 2004). Peningkatan oksidasi FFA akan menurunkan oksidasi karbohidrat dan berdampak pada penurunan laktat darah.

Tujuan dari penelitian ini adalah untuk mengetahui pengaruh kopi arabika setelah latihan fisik intensitas submaksimal terhadap kadar laktat darah dan kadar glukosa darah sebagai parameter pemulihan dan kelelahan.

\section{Metode Penelitian}

Penelitian ini telah disetujui oleh Komite Etik Fakultas Kedokteran Universitas Airlangga Surabaya, Jawa Timur, Indonesia.
Subjek. Penelitian ini melibatkan 33 subjek sehat tidak terlatih $( \pm 20$ tahun, mahasiswa) yang dibagi secara acak menjadi 3 kelompok: kelompok kontrol, kelompok kopi 1, dan kelompok kopi 2. Kelompok kontrol diberi air mineral. Kopi yang digunakan dalam penelitian ini adalah kopi arabika gayo. Kelompok kopi 1 meminum 15 gram kopi dalam $200 \mathrm{~mL}$ air mineral. Kelompok kopi 2 meminum 20 gram kopi dalam $200 \mathrm{~mL}$ air mineral (Aritanoga et al., 2019).Prosedur dan instrumen. Semua subjek puasa selama kurang lebih 8 jam. Laktat darah puasa (laktat_P) dan glukosa darah (GDP) diukur. Kemudian, minuman manis (1 sendok makan gula dalam $200 \mathrm{~mL}$ air) diberikan kepada semua subjek. Setelah 30 menit, semua subjek melakukan tes Rockport sebagai latihan intensitas submaksimal. Segera setelah latihan, semua subjek diukur laktat darah (Laktat_post1) dan glukosa darah (GD_post1) dan dilanjutkan minum air mineral untuk kelompok kontrol dan kopi untuk kelompok perlakuan (kopi1 dan kopi2). Sekitar 60 menit kemudian, laktat darah (Laktat_post2) dan glukosa darah (GD_post2) diperiksa.

Laktat darah dianalisis menggunakan accutrend plus lactate meter dan glukosa darah diukur menggunakan accuchek glucometer. Analisis statistik

Uji normalitas digunakan untuk menentukan distribusi data. Bila data berdistribusi normal digunakan uji Anova, jika tidak berdistribusi normal dilakukan uji Kruskal-wallis. Jika hasil uji Anova berbeda nyata maka dilanjutkan dengan uji post-hoc LSD. Jika hasil Kruskal wallis berbeda nyata maka akan diuji dengan mann-whitney.

\section{Hasil}

Data semua variabel terdapat pada tabel 1. Kadar laktat pada keadaan puasa (Laktat_P) dan kadar glukosa darah puasa (GDP) menunjukkan perbedaan yang tidak

JBP Vol.23, No.02, Desember 2021- Hadyan Zulfahmi, Hadiq Firdausi, Purwo Sri Rejeki, Lilik 
Jurnal Biosains Pascasarjana Vol. 23 (2021) pp

(C) (2021) Sekolah Pascasarjana Universitas Airlangga, Indonesia

bermakna. Hal ini menandakan bahwa subjek berada dalam keadaan yang relatif homogen.

Tabel 1. Laktat darah ( $\underline{\mathrm{mmol} / \mathrm{L}) \text { dan }}$ glukosa darah (mg/dL) di setiap grup

\begin{tabular}{lcrrr} 
& Laktat_P & Laktat_Postl & Laktat_Post2 \\
\hline Kontrol & $1.71 \pm 0.677$ & $4.36 \pm 1.536$ & $2.76 \pm 1.185$ \\
Kopi 1 & $1.50 \pm 0.534$ & $4.89 \pm 1.293$ & $2.36 \pm 0.347$ \\
Kopi 2 & $2.14 \pm 0.813$ & $4.62 \pm 1.416$ & $2.75 \pm 0.466$ \\
\hline
\end{tabular}

data $=$ mean $\pm S D$

\begin{tabular}{rrr}
\multicolumn{1}{c}{ GDP } & \multicolumn{1}{c}{ GD_postl } & \multicolumn{1}{c}{ GD_post2 } \\
\hline $82.9 \pm 14.36$ & $77.7 \pm 13.30$ & $92.9 \pm 15.63$ \\
$86.6 \pm 7.30$ & $83.7 \pm 9.14$ & $99.5 \pm 9.55$ \\
$87 \pm 8.34$ & $83.6 \pm 7.94$ & $96.3 \pm 10.22$ \\
\hline
\end{tabular}

Tidak ada perbedaan signifikan antar grup. Analisis statistic menggunakan tes ANOVA.

Laktat darah tampak memiliki pola yang sama dan perbedaan antara pasca olahraga dan setelah minum kopi 1 jam ( $\triangle$ Laktat_Post1\&Post2) menunjukkan perbedaan yang signifikan (Gambar. 1). Namun ada kecenderungan kelompok perlakuan lebih banyak mengalami penurunan dibandingkan kelompok kontrol.
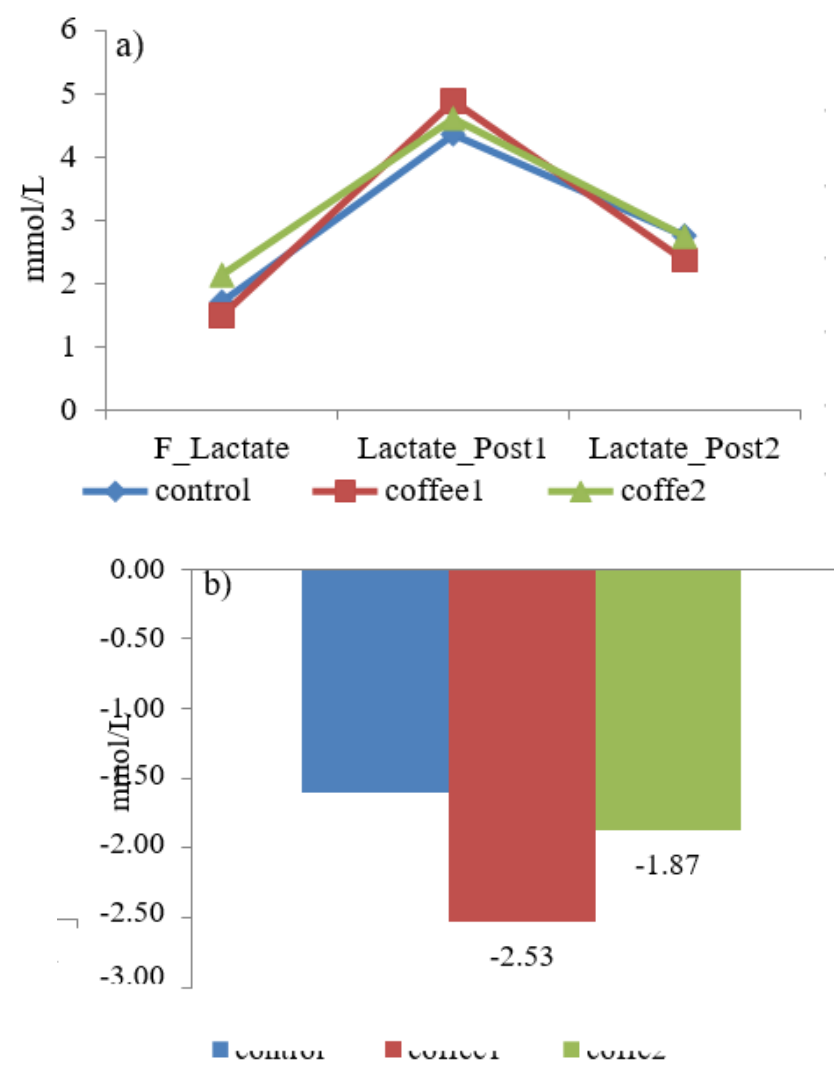

Gambar. 1. Profil kadar laktat darah di setiap kelompok (mmol/L). a) Pola kadar laktat darah berdasarkan waktu Laktat_P (laktat darah puasa)); Laktat_Post1 (laktat darah setelah latihan fisik); Laktat_Post2 (laktat darah setlah 60 menit pemberian kopi). b) Perbedaan laktat darah ( $\Delta$ laktat_Post1\&Post2 dalam $\mathrm{mmol} / \mathrm{L}$ ) antara segera setelah berolahraga dan setelah 60 menit minum kopi. Tidak ada perbedaan yang signifikan antar kelompok. Analisis statistik dilakukan dengan menggunakan uji Anova. '

- Kadar glukosa darah 1 jam setelah pemberian kopi meningkat pada semua kelompok. Hal yang menarik adalah pada kelompok kopi 2 adalah yang terendah dibandingkan dengan yang lain. Namun tidak ada perbedaan yang signifikan antar kelompok
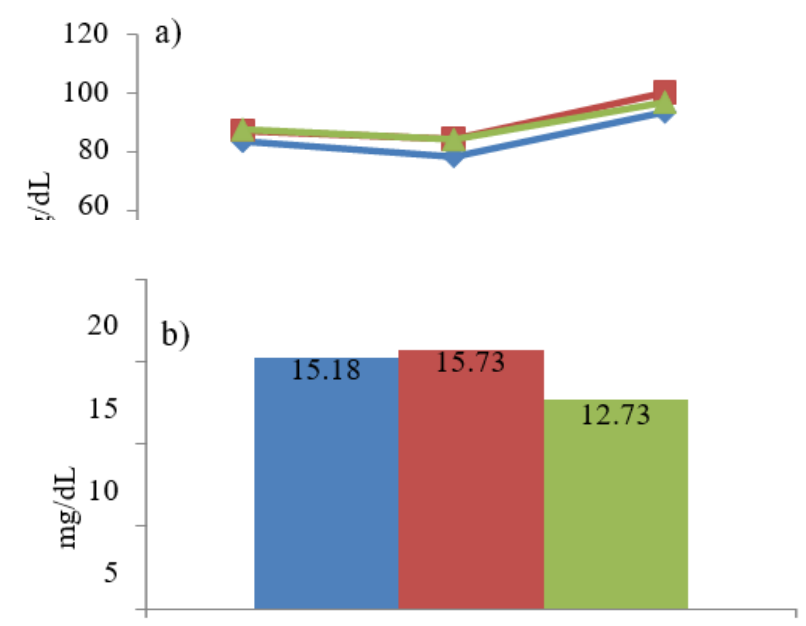

$$
\begin{gathered}
\Delta \mathrm{BG} \_ \text {post } 1 \& \text { post } 2 \\
\square \text { control } \quad \square \text { coffee } 1 \quad \square \text { coffee } 2
\end{gathered}
$$

JBP Vol.23, No.02, Desember 2021- Hadyan Zulfahmi, Hadiq Firdausi, Purwo Sri Rejeki, Lilik

Herawati

DOI 10.20473/jbp.v5i2.2021.6-11 
Gambar. 2. Profil kadar glukosa darah di setiap kelompok (mg/dL). a) Pola kadar glukosa darah berdasarkan waktu. GDP (Glukosa Darah Puasa); BGpost1 (blood glucose after exercise); BGpost2 (blood glucose after 60' drank coffee). b) Perbandingan kadar glukosa darah $(\mathrm{mg} / \mathrm{dL})$ antara segera setelah latihan fisik dan setelah 60 menit minum kopi. Tidak ada perbedaan yang signifikan antar kelompok. Analisis statistik dilakukan dengan menggunakan uji Anova.

\section{Pembahasan}

Kadar laktat darah 60 menit setelah pemberian kopi arabika mengalami penurunan pada masing-masing kelompok. Penurunan kadar laktat darah yang terjadi pada masing-masing kelompok tidak memiliki perbedaan yang signifikan. Namun dari tren penurunan yang terjadi, penurunan kadar laktat terbesar terjadi pada kelompok kopi 1. Ketidakbermaknaan dalam penelitian ini dapat disebabkan oleh dosis kopi yang diberikan kepada subjek atau media pemberian kafein berupa kopi arabika yang mungkin belum terpenuhi.

Beberapa penelitian belum menunjukkan penurunan kadar laktat darah setelah pemberian kafein, tetapi peningkatan kadar laktat darah setelah pemberian kafein. Hal tersebut berbeda dengan hasil penelitian ini yang menunjukkan adanya penurunan kadar laktat darah setelah pemberian kopi arabika. Jackman and Collagues (1996) melakukan penelitian tentang efek kafein selama latihan fisik dan menemukan bahwa terjadi peningkatan kadar laktat darah setelah suplementasi kafein. Van Soeren dan Graham (1996) menemukan metabolisme kafein setelah fase penarikan dan melaporkan bahwa laktat darah meningkat sebagai respons terhadap aktivitas fisik dan konsumsi kafein.

Penurunan kadar laktat darah yang tidak bermakna setelah kopi arabika ini sejalan dengan penelitian yang dilakukan oleh Siahpoosh dan Nesaei (2016) bahwa tidak terdapat perbedaan kadar laktat darah yang signifikan setelah pemberian kafein menggunakan permen karet antara masingmasing kelompok dengan dosis tertentu. Selain itu, pengaruh penurunan kadar laktat darah setelah latihan fisik dengan pemberian kafein sejalan dengan penelitian yang dilakukan oleh Mahdavi et.al (2015) yang menemukan bahwa peningkatan kadar laktat darah setelah latihan fisik lebih rendah pada kelompok dengan suplementasi kafein. dibandingkan dengan kelompok yang hanya diberi plasebo

Penelitian tentang efek kafein yang terkandung dalam kopi arabika terhadap laktat setelah latihan fisik masih belum banyak dibahas dan beberapa yang melakukan penelitian tentang kafein menunjukkan hal yang bertentangan dengan efek glikogen pada kafein yang menurunkan efek penurunan laktat darah. Efek sparring glikogen adalah meningkatkan oksidasi asam lemak bebas dan penggunaan glikogen otot (Jacobson et.al, 2001). Kadar glukosa darah setelah kopi arabika meningkat pada masing-masing kelompok. Peningkatan kadar glukosa darah terbesar terjadi pada kelompok kopi1 sebesar 15.727 \pm 9.8396 $\mathrm{mg} / \mathrm{dl}$. Peningkatan kadar glukosa pada masing-masing kelompok tersebut tidak memiliki perbedaan yang signifikan. Peningkatan kadar glukosa setelah mempersembahkan kopi arabika ini sejalan 
dengan penelitian yang dilakukan oleh

Khakim (2015) bahwa peningkatan kadar glukosa darah 30 menit setelah kopi lebih tinggi dibandingkan dengan plasebo. Penelitian lain juga menemukan bahwa terjadi peningkatan kadar glukosa darah 30 menit setelah mengkonsumsi kafein dari minuman coca-cola (Hutapea et al.

2016). menurut Lee et al. (2005) kafein dapat menurunkan ambilan glukosa yang menyebabkan peningkatan kadar glukosa darah. Namun, ada beberapa penelitian lain yang menemukan penurunan kadar glukosa darah setelah kafein. Purwaningsih (2017) menemukan bahwa pemberian kopi Robusta kepada orang yang berpuasa menurunkan kadar glukosa darah. Selain itu, Sayogo (2011) menemukan bahwa penurunan kadar glukosa darah setelah mengkonsumsi kopi disebabkan oleh kopi yang memiliki polifenol yaitu asam klorogenat yang berfungsi sebagai antioksidan kuat yang akan merangsang pembentukan GLP-1 (glukagon lepepeptide-1) sehingga membuat pankreas lebih reaktif terhadap glukosa darah dan meningkatkan sekresi insulin.

\section{Kesimpulan}

Pemberian kopi setelah latihan intensitas submaksimal tidak berpengaruh terhadap peningkatan laktat darah dan glukosa darah pada remaja. Namun, pemberian kopi 15 gram cenderung menurunkan kadar laktat darah lebih banyak dibandingkan pemberian kopi 20 gram lainnya. Pemberian kopi 20 gram memiliki kecenderungan untuk banyak menurunkan kadar glukosa darah. Temuan ini masih membutuhkan eksplorasi lebih lanjut untuk mengetahui mekanisme yang mendasarinya.

\section{Konflik Kepentingan}

Penulis menyatakan tidak memiliki konflik kepentingan dalam artikel ini.

\section{Referensi}

Acheson, K., Gremaud, G., Meirim, I., Montigon, F., Krebs, Y., Fay, L., Gay, L., Schneiter, P., Schindler, C. and Tappy, L. (2004). Metabolic effects of caffeine in humans: lipid oxidation or futile cycling? The American Journal of Clinical Nutrition, 79(1), pp.40-46.

Aritanoga, M., Effendi, C. \& Herawati, L. 2019. Setelah Latihan Fisik Akut Submaksimal Pada Pria Sedenter (Gayo-Arabica Coffee Decreases MDA and Increases SOD After Single Bout Submaximal Physical Exercise In Sedentary Men). Sumberdaya Hayati, $5(1)$.

Billat, L.V., 1996. Use of blood lactate measurements for prediction of exercise performance and for control of training. Sports medicine, 22(3), pp.157-175.

Graham, T.E. 1996. Spriet L.Sports science exchange: Caffeine and exercise performance.Vol 9; number 1

Hutapea, G.C., Ariosta, A. and Hardian, H., 2016. Perbandingan Kadar Glukosa Darah Setelah Mengonsumsi Coca-Cola Reguler dan Coca-Cola Zero Pada Populasi NonDiabetes. Jurnal Kedokteran Diponegoro, 5(4), pp.892-902.

Jackman, M., Wendling, P., Friars, D. and Graham, T. (1996). Metabolic, catecholamine, and endurance responses to caffeine during intense exercise. 
Journal of Applied Physiology, 81(4), pp.1658-1663.

Jacobson, T.L., Febbraio, M.A., Arkinstall, M.J. and Hawley, J.A., 2001. Effect of Siahpoosh, A. K., \& Nesaei, A. (2016). The Effect of Caffeine Supplementation on Blood Lactate and Glucose after 800 and 1500 meter Run. Biomedical and Pharmacology Journal, 9(1), 97-103.

Silverthorn, D. U. 2004. Skeletal muscle. Human physiology: an integrated approach. 3rd ed.

San Francisco: Daryl fox publisher, 71-75.

Strojnik, V., \& Komi, P. V. 1998. Neuromuscular fatigue after maximal stretch-shortening cycle exercise. Journal of Applied Physiology, 84(1), 344-35. caffeine co- ingested with carbohydrate or fat on metabolism and performance in endurancetrained men. Experimental Physiology, 86(1), pp.137-144.

Khakim, L., 2016. Efek Pemberian Kopi Terhadap Glukosa Darah Dan Laktat Darah Selama Dan Sesudah Aktifitas Fisik

Submaksimal. Jurnal Sport Science, 4(3), pp.162-165.

Lee, S., Hudson, R., Kilpatrick, K., Graham, T. E., \& Ross, R. (2005). Caffeine ingestion is associated with reductions in glucose uptake independent of obesity and type 2 diabetes before and after exercise training. Diabetes Care, 28(3), 566-572.

Mahdavi, R., Daneghian, S., Jafari, A., \& Homayouni, A. (2015). Effect of acute caffeine supplementation on anaerobic power and blood lactate levels in female athletes. Journal of Caffeine Research, 5(2), 83-87.

McArdle, W. D., Katch, F. I., \& Katch, V. L. 2001. Energy transfer in the body. Exercise Physiology: Energy Nutrition and
Human Performance. 5th ed. Baltimore, MD: Lippincott Williams \& Wilkins, 131-156.

Vita Purwaningsih, Nur. (2017). Perbandingan Kadar Glukosa Darah Sebelum Dan Sesudah Minum Kopi. THE JOURNAL OF MUHAMMADIYAH MEDICAL LABORATORY TECHNOLOGIST. 1. 61. 10.30651/jmlt.v1i1.1009.

Widiyanto, 2007. Latihan Fisik dan Laktat. Jurnal Midikora FIK UNY.

Sayogo dan Mutu., 2011. Fruktooligosakarida dan Pengaruhnya Terhadap Hormon Glucagon- like-peptida-1 Pada Penyandang Diabetes Millitus Tipe 2. 2(21), Karya Tulis Ilmiah. Universitas Sumatera Utara. 